\title{
Requirements Gathering with diverse user groups and stakeholders
}

\begin{tabular}{|c|c|}
\hline Maggie Morgan & Chris Martin \\
\hline School of Computing & School of Computing \\
\hline University of Dundee & University of Dundee \\
\hline Scotland, DD1 4HN & Scotland, DD1 4HN \\
\hline NewellMorgan@yahoo.co.uk & cjmartin@computing.dunc \\
\hline Marilyn McGee-Lennon & Julia Clark \\
\hline Dept. of Computing Science & Dept. of Comp. Sci. \& Mat \\
\hline University of Glasgow & University of Stirling \\
\hline Scotland, G12 8QQ & Scotland, FK9 4LA \\
\hline mcgeemr@dcs.gla.ac.uk & jsc@cs.stir.ac.uk \\
\hline Nick Hine & Maria Wolters \\
\hline School of Computing & CSTR, 2 Buccleuch Place \\
\hline University of Dundee & University of Edinburgh \\
\hline Scotland, DD1 4HN & Scotland, EH8 9LW \\
\hline
\end{tabular}

John Arnott

School of Computing

University of Dundee

Scotland, DD1 4HN

jarnott@computing.dundee.ac.uk

\begin{abstract}
An interactive theatre piece has been designed to

facilitate requirements gathering with a diverse range of user groups and stakeholders within the conceptual stage of telecare equipment for the home environment. The piece was devised and produced by theatre professionals in consultation with computer engineers as part of a major research programme developing computer systems to support older and disabled people. By the interaction of a researcher, two actors and some video clips, the piece will demonstrate:
\end{abstract}

a) the vital importance of all stakeholders being properly consulted and for them to inter-communicate, and

b) the role of theatre as a tool in this process.

The rationale and methodology of this technique will be discussed in an interactive session with the audience.

\section{KEYWORDS}

User-centred Design, Requirements Gathering, Multiple and diverse user groups, interactive forum theatre,

Telecare.

\section{ACM Classification Keywords}

H.5.2 [Information Interfaces and Presentation]: User Interfaces: User-centered design. D.2.2 [Software Engineering]: Design Tools \& Techniques: User Interfaces. 


\section{Requirements gathering for telecare}

The increasing percentage of older people and disabled people in the world raises the economic problems of caring for this group [5]. It is much less costly if people can stay within their own homes rather than be in hospitals or other institutions, and this has led to a requirement for "smart homes" and telecare systems to be provided within domestic environments. The requirements gathering challenge for this type of equipment lies in the large number of stakeholders and the very diverse user groups that would be involved in the specification, procurement and use of such equipment. These include designers and developers, older people themselves (who can be both personally in need of the technology and/or are acting as carers), younger informal carers (friends and family), professional carers, health professionals and bureaucrats within the social care profession. An important section of these users will include a large percentage of people who are technologically naïve, if not techno-phobic.

Requirements gathering for systems with these characteristics need to identify the differing and sometimes contradictory views of all stakeholders/ users, with a view to producing an agreed and possibly compromise set of requirements for the system.

Ideally it would be valuable to allow such people to interact as a mixed group including representatives of all stakeholders.

\section{Requirements gathering in the context of} multiple stakeholders

Designers, engineers, health and social work

professionals, older people and family carers are very diverse groups. Each group will have its own context, agenda and jargon, which is understood within each group. Interdisciplinary consultation and discussion within such diverse groups, however, creates

challenges as each group's context, agenda and jargon will be different. The ultimate users of the technology, older frailer people, will have their own context, agenda and language, which will usually be not at all technical and often highly individual, according to each older user's needs. They will mostly not understand the technical aspects and language of the designers and possibly be dubious about the (often conflicting) agendas and necessarily wider perspectives of the social work and health professionals.

Interdisciplinary discussion also can be hindered, not only by the 'professionals' having different agendas, but by older people and their informal carers feeling intimidated and inhibited in a formal public discussion. It is thus particularly important to set up a "risk free" situation where stakeholders feel free to articulate their views without appearing to personally attack other stakeholder groups. This can be achieved by the use of theatre.

\section{Interactive Forum Theatre}

The form of interactive theatre used is based on and developed from the work of the Brazilian dramatist, Augusto Boal [1]. He developed Forum Theatre on the streets of Rio de Janeiro initially as a way of permitting issues to be debated by ordinary people during the time of a very repressive political regime. This has been further developed by Morgan, a professional scriptwriter/director for use within health care and computer research environments [2] 
The format consists of a 'story' which is scripted in close collaboration with the researcher(s). Professional actors are carefully briefed to create 'real', believable characters both for the scripted performance and for the subsequent extemporary dialogue with the audience. A trained facilitator provides the interface between the 'story' and the audience, and encourages the audience to debate the issues raised and related issues. The format allows the audience to interact with the actors, who stay in role, and where appropriate, the audience itself can change the story, or propose changes which are then enacted. At crucial points in the story, the facilitator enables the audience to discuss, debate and further the ideas and concepts [3].

\section{Forum Theatre - an equalising and safe methodology for requirements gathering}

The story contains believable characters who are trying to interface with technology. It is based on a strong (non-technologically focused) story-line, including humour and tension between characters, rather than a documentary describing the technology. This type of presentation encourages the audience to engage fully with the characters in the story. It enables the facilitator to raise important and sensitive issues but to project all comments, reactions, criticisms, etc., onto the characters (played by professional actors) rather than other members of the audience. This gives the multiple stakeholders in the audience a freedom to question and also to contribute their knowledge and experience without offending anyone. The story also keeps the focus, as diverging discussion can be drawn back to the immediate issues raised in the story. This produces a liberated, wide-ranging but focused discussion and permits audience members to hear a range of ideas and perspectives, increasing their understanding of other stakeholders' perspectives and problems. In addition it has been found that the audience enjoys and becomes very much more engaged in the discussions than is usual in more traditional focus groups.

This technique is offered to the $\mathrm{CHI}$ community as a novel and effective way of requirements gathering,

particularly for situations where multiple stakeholders/ user groups have different characteristics and agendas.

\section{The format of the presentation}

The 10-minute presentation will be based on the forum

theatre research format staged previously in the Wolfson Research Theatre at the School of Computing at the University of Dundee [4]

The very simple set that will be used will illustrate the way in which theatre can "suspend disbelief". It will consist of minimum furniture, plus props which will simulate the telecare technology, plus a projected image to simulate touch screens on the walls of the "home", that would provide data and control mechanisms for the technology.

A researcher will introduce the event briefly and enter into dialogue with "Peggy", a character in the story.

Their brief conversation will give the background story; that of Peggy, crippled by arthritis and her husband "Bill", who had given up his social life in order to look after Peggy. Their struggle to remain in their own home hit a huge problem when Bill had a mild stroke, and he now has impaired short-term memory.

This is followed in the presentation by a few seconds' video playback of a discussion between their daughter, 
a care manager and a telecare engineer, where the couple's needs are being discussed.

Peggy and Bill are then seen live, interacting with telecare aids that the engineer has specified, and the positive and negative effects on their quality of life emerge.

\section{Conclusion}

The theatrical performance is designed to challenge the audience's beliefs and perspectives by showing the complexity of designing technology for older people, and demonstrates a method which was developed for encouraging interaction between older people and researchers. It will underline the importance of intercommunication between multiple stakeholders within the context of designing technology to enable frail older people to function in their own homes. It is designed to be an enjoyable experience, which is an important factor in making it memorable, both within the context of a real situation and as a demonstration to $\mathrm{a} \mathrm{CH} I$ audience.

The piece will show that the professional quality of the writing, direction, acting and facilitating contribute hugely to the engagement of an audience and makes a piece memorable. In a research environment this ensures that the data obtained from the audience is relevant and of high quality.

The piece will also be valuable in illustrating how the use of well-written drama can be directly relevant to any situation where multiple stakeholders/users with different characteristics and agendas are involved in requirements gathering.

\section{Acknowledgments}

This research was supported by the UK Engineering and Physical Sciences Research Council (EPSRC), The Scottish Higher Education Funding Council (SHEFC/SFC) and the Leverhulme Trust.

\section{References}

11] Boal, A. The Rainbow of Desire. Routledge, London, UK, 1995.

[2] Morgan M., and Newell, A. Interface between two disciplines - the development of theatre as a research tool. In Proc. HCI International, Part I., Lecture Notes in Computer Science 4550, Springer (2007), 184-193.

[3] Newell, A.F., Carmichael, A., Morgan, M., and Dickinson, $A$. The use of theatre in requirements gathering and usability studies. Interacting with Computers 18, 5 (2006), 996-1011.

[4] Newell, A. F., Gregor P., and Alm, N. HCI for older and disabled people in the Queen Mother Research Centre at Dundee University, Scotland. Ext. Abstracts CHI'06, ACM Press (2006), 299-302.

[5] Scottish Executive. First Report for the Range and Capacity Review: Projections of Community Care Services Users, Workforce and Costs. Edinburgh, Scotland, UK, 2004. 